\title{
Performance Evaluation of Membership Functions on Fuzzy Logic Controlled AC Voltage Controller for Speed Control of Induction Motor Drive
}

\author{
J. Gayathri Monicka \\ Department of EEE \\ Bharath University, Chenni -73, India.
}

\author{
Dr. N.O.Guna Sekhar \\ Department of EEE \\ Bharath University, Chenni -73 India.
}

\author{
K. Ramash Kumar \\ Department of EEE \\ A.M.S. College of Engineering, Anna University, Chennai -55, India.
}

\begin{abstract}
The objective of this paper is to investigate the effect of membership functions in the fuzzy control (FC) of an ac voltage controller for speed control of induction motor drive. A Sugeno type FC for closed loop control of induction motor drive fed by ac voltage controller is designed and considered for evaluation. The controller is used to change the firing angle of the ac volage controller and thereby, the voltage fed to stator of induction motor to regulate the speed. Sugeno type FC is selected for evaluation, as it is easy to implement in simulation. The membership functions selected for evaluation are triangular, trapezoidal, Gaussian and bell shaped functions. The different membership function evaluation is done considering seven linguistic sets for error and change in error. The simulation model of different membership functions in the fuzzy control (FC) of an ac voltage controller for speed control of induction motor drive is implemented in Matlab/simulink The results of the simulated performances are compared. The triangular membership function shows better performance compared to other membership functions.
\end{abstract}

Keywords - AC voltage controller, Induction motor drive, Fuzzy control (FC).

\section{INTRODUCTION}

The speed control of three phase induction motor can be achieved by variation of stator voltage using three phase ac voltage controller. This controller consists of six thyristors (like silicon controlled rectifier (SCR)) as shown in Fig. 1. The ac voltage controller converts fixed mains supply voltage directly to variable alternating voltage without a change in the frequency. It is mainly used in speed control of polyphase induction motor, domestic and industrial heating and light control. This system has been used in speed control of three phase induction motor in many literatures [1-6]. The traditional controllers based speed control of induction motor using ac voltage controller has been reported many literatures [7-9]. The general traditional controllers are widely used for ac voltage controller based speed control of induction motor application control. But it does not give satisfactory results when loading variation condition, control parameters and motor itself are changed. In recent years, the artificial intelligent (AI) techniques, such as, fuzzy controller (FC) has shown high potential for induction motor control applications [10]. Fuzzy logic controller has the advantage that it can be designed without the exact model of the system. This approach of FC design guarantees the stable operation even if there is a change in the parameters of induction motor and sudden load variation. Fuzzy logic controller for motors has been analyzed in detail in the literature. Various fuzzy controllers like fuzzy PI, fuzzy PD and fuzzy PID controller responses have been analyzed for dc motor speed control [11-13]. In this paper, Sugeno type of fuzzy controller at different membership function is evaluated for a speed control of ac voltage controller fed induction motor drive. The effect of membership functions in the fuzzy control of an ac voltage controller for speed control of induction motor drive is studied in Matlab/Simulink. The analysis is done for different types of membership functions.

\section{PROPOSED SYSTEM}

In Fig. 1 shows the three phase ac voltage controller fed induction motor drive. It consists of three phase ac supply; thyristors based three phase ac voltage controller, induction motor, fuzzy controller and firing pulse unit. The induction motor model in stationary reference frame has been used in the simulation [14]. The three phase ac voltage is provided to three phase ac voltage controller, which consists of three legs, each leg having the two thyristors is connected in anti- parallel mode for bidirectional operation purpose. The output voltage of ac voltage controller or stator voltage of induction motor controlled by changing firing angle. The speed of induction motor is controlled by variation of stator voltage. The error and change in error signals of Sugeno type fuzzy controller [15] is obtained by difference of feedback speed and refernce speed, the control output signal or changing firing angle of fuzzy controller compared with refernce carrier signal to generate the firing pulses to drive gating thyristors of three ac voltage controller to regulate stator voltage induction motor as well as speed of induction motor. The detailed design of fuzzy controller at various membership functions, simulation results are given in subsequent sections.

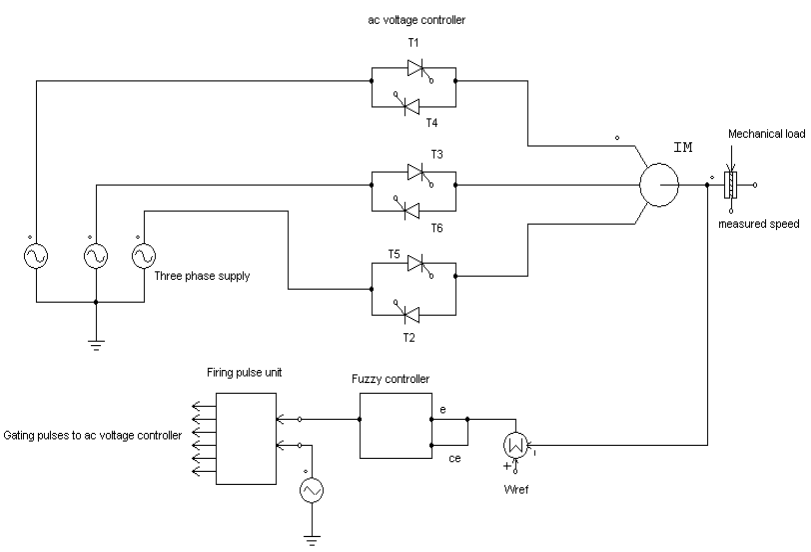

Figure 1. Three phase ac voltage controller under the induction motor. 


\section{FUZZY LOGIC CONTROLLER}

Fuzzy logic control is derived from fuzzy set theory introduced by Zadeh in 1965 . In fuzzy set theory, the transition between membership and non-membership can be gradual. Therefore, boundaries of fuzzy sets can be vague and ambiguous, making it useful for approximate systems [15-16]. The FLC is an attractive choice when precise mathematical formulations are not possible. Other advantages of FLC are

1. It can work with less precise inputs.

2. It does not need fast processors.

3. It needs less data storage in the form of membership functions and rules than conventional look up table for nonlinear controllers.

4. It is more robust than other non-linear controllers.

\subsection{Fuzzification}

Fuzzy logic uses linguistic variables instead of numerical variables. The process of converting a numerical variable (real number or crisp variable) into a linguistic variable (fuzzy number) is called fuzzification. The simplest form of membership function is triangular membership function and it is used here as the reference. The Fig. 2 shows the spread of membership functions for the inputs and output. As Sugeno type of implication is considered, the singleton membership function is used for the output variable namely the change in duty cycle. Error is normalized by dividing the actual error in speed with the reference speed. This normalization is useful for using the fuzzy controller for any speed reference.

\subsection{Defuzzification}

The reverse of fuzzification is called defuzzification. The use of FLC inference engine produces required output in a linguistic form. According to real world requirements, the linguistic variables have to be transformed to crisp output. Weighted average method is the best well-known defuzzification method for Sugeno type fuzzy controller and is used in this work. This method has the advantage of easy implementation in simulation.

\subsection{Rule base table and inference engine}

The rules are in the format - 'If error is $\mathrm{Ai}$, and change in error is $\mathrm{Bi}$ then output is $\mathrm{Ci}$ '. Here the if 'part' of a rule is called the rule-antecedent and is a description of a process state in terms of a logical combination of atomic fuzzy propositions. The 'then' part of the rule is called the rule consequent and is a description of the control output in terms of logical combinations of fuzzy propositions. The rules for the designed fuzzy controller are given in the Table I. Table I uses seven linguistic variables for the error and change in error with 49 rules.

The seven sets used for fuzzy variables 'error' and 'change in error' are negative big (NB), negative medium (NM), negative small (NS), zero $(\mathrm{Z})$, positive big (PB), positive medium (PM) and positive small (PS). From the rule table, the rules are manipulated as - If error is NB and change in error is NB, then output is NB. The actual motor speed is fed back and is compared with set speed. After comparison, error signal and the change in error are calculated and are given as input to fuzzy controller. In this work, the error is normalized to per unit value with respect to the set speed. This helps in using the fuzzy controller for any set speed. The fuzzy controller will attempt to reduce the error to zero by changing firing angle of switching signal.

\subsection{Membership function for evaluation}

Membership functions can have different shapes. The most commonly used shapes are triangular, trapezoidal, Gaussian and bell shaped membership functions. In this work, the response of the speed control of ac voltage controller fed induction motor drive is evaluated by considering the membership functions like triangular, trapezoidal, Gaussian and bell shaped. Fig. 3 shows the spread of the various functions used for seven variables.
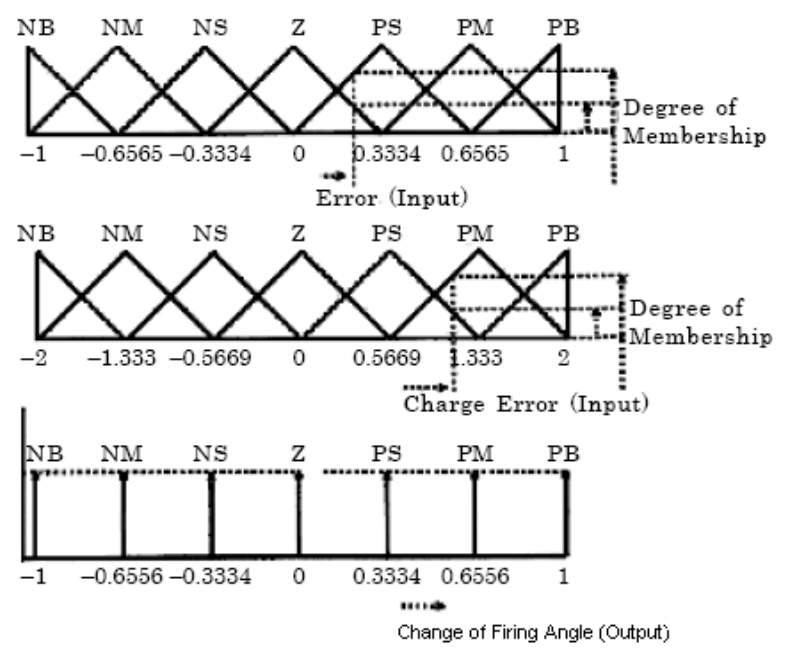

Figure 2. Spread of fuzzy memberships.

Table 1 Rule Base Table with 49 Rules.

\begin{tabular}{|c|c|c|c|c|c|c|c|}
\hline e $/$ ce & NB & NM & NS & Z & PS & PM & PB \\
\hline NB & NB & NB & NB & NB & NM & NS & Z \\
\hline NM & NB & NB & NB & NM & NS & Z & PS \\
\hline NS & NB & NB & NM & NS & Z & PS & PM \\
\hline Z & NB & NM & NS & Z & PS & PM & PB \\
\hline PS & NM & NS & Z & PS & PM & PB & PB \\
\hline PM & NS & Z & PS & PM & PB & PB & PB \\
\hline PB & Z & PS & PM & PB & PB & PB & PB \\
\hline
\end{tabular}
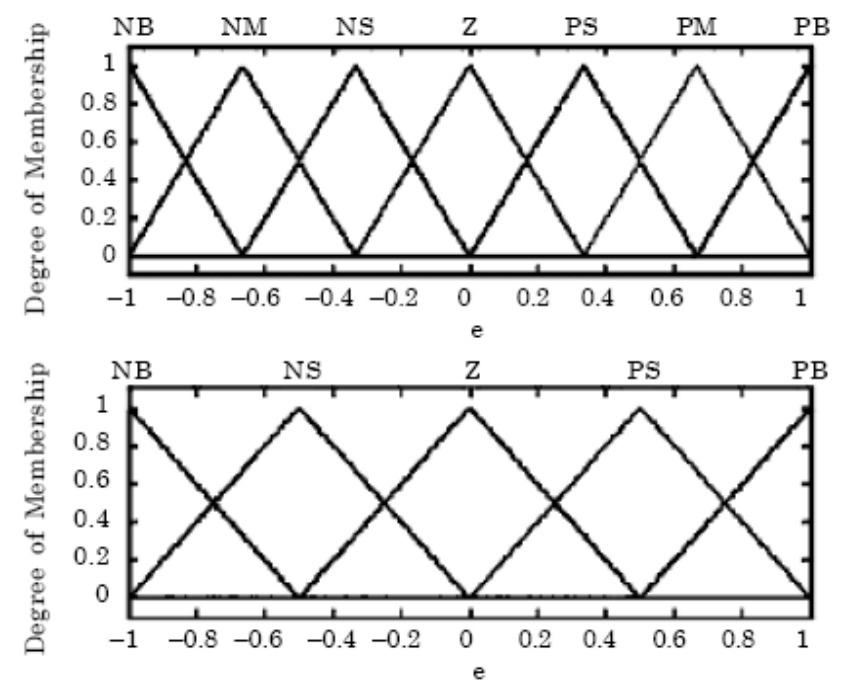

Figure 3 (a). Spread of fuzzy membership for triangular functions. 


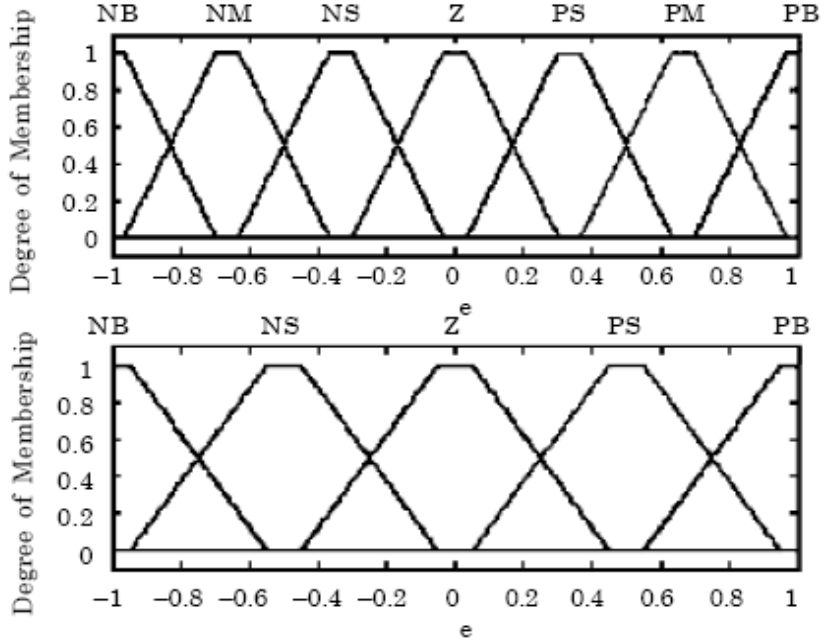

Figure 3 (b). Spread of fuzzy membership for trapezoidal functions.

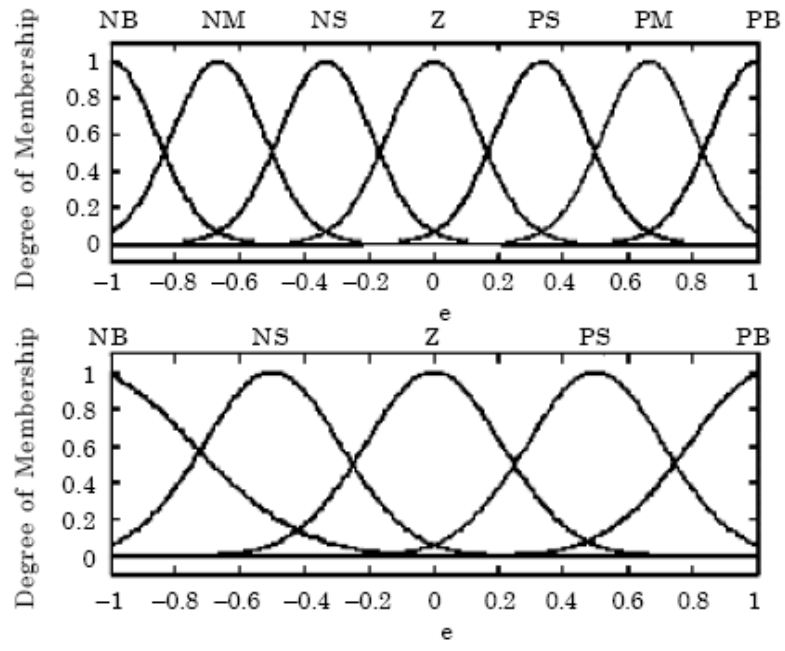

Figure 3 (c). Spread of fuzzy membership for Gaussian functions.

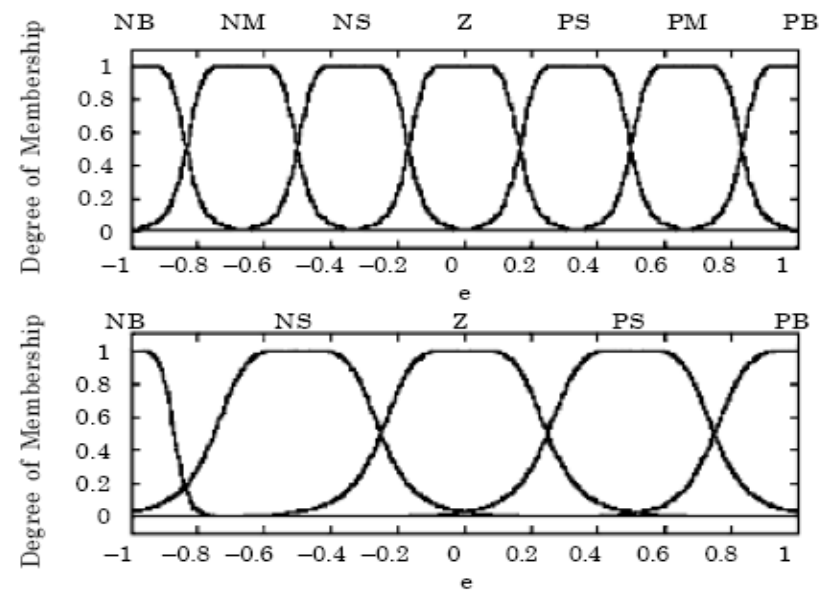

Figure 3 (d). Spread of fuzzy membership for bell shaped functions.

\section{SIMULATION RESULTS}

The simulation of ac voltage controller fed induction motor drive is done in MATLAB/Simulink toolbox. The Matlab/Simulink simulation model of proposed system is depicted in Fig. 4. The fuzzy toolbox is used to test in evaluating the proposed fuzzy controller. The parameters of the induction motor and ac voltage controller used are listed in the
Table II. This controller is used to change the firing angle of the ac voltage controller and thereby, the voltage fed to stator of induction motor to regulate the speed. Sugeno type fuzzy controller is selected for evaluation, as it is easy to implement in simulation. The computer simulation is run for a step change in load torque is applied to induction motor and the corresponding change in the speed is recorded. The motor reference speed is set at $1450 \mathrm{rpm}$ and the actual motor speed is recorded. The load is initially $4 \mathrm{~N}-\mathrm{m}$ and then changed to load $2 \mathrm{~N}-\mathrm{m}$ at $1 \mathrm{~s}$. The simulated results are given in Fig. 5.

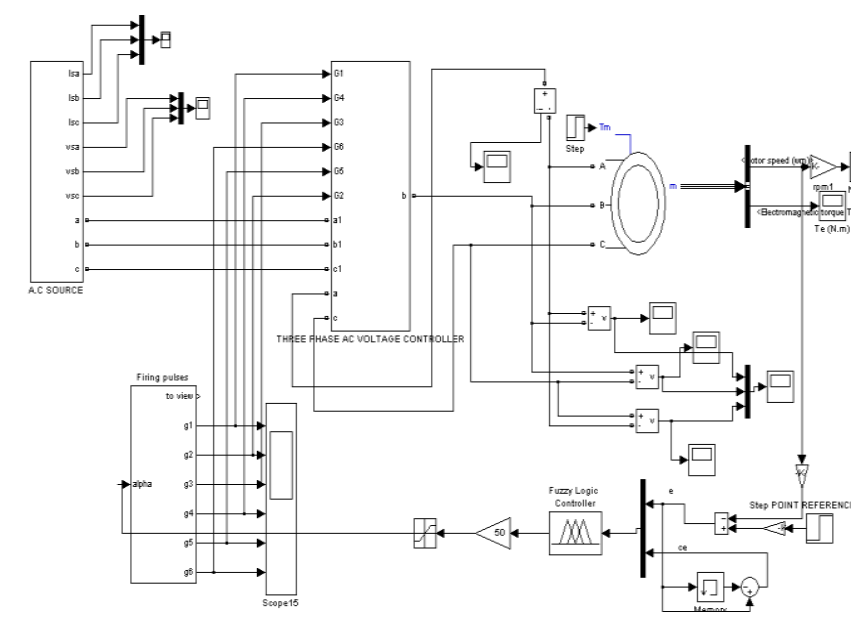

Figure 4. Simulation simulink model of proposed system.

Table 2 Parameters of Induction motor.

\begin{tabular}{|l|c|}
\hline \multicolumn{1}{|c|}{$\begin{array}{c}\text { Induction motor } \\
\text { parameters }\end{array}$} & Value \\
\hline Line voltage & $420 \mathrm{~V}$ \\
\hline Power rating $(\mathrm{P})$ & $245.19 \mathrm{~W}$ \\
\hline Supply frequency $(\mathrm{f})$ & $50 \mathrm{~Hz}$ \\
\hline Stator resistance $\left(\mathrm{R}_{\mathrm{s}}\right)$ & $0.435 \mathrm{Ohm}$ \\
\hline Stator inductance $\left(\mathrm{L}_{\mathrm{s}}\right)$ & $4 \mathrm{mH}$ \\
\hline Rotor resistance $\left(\mathrm{R}_{\mathrm{r}}\right)$ & $0.816 \mathrm{Ohm}$ \\
\hline Rotor inductance $\left(\mathrm{L}_{\mathrm{r}}\right)$ & $1 \mathrm{mH}$ \\
\hline Mutual inductance $\left(\mathrm{L}_{\mathrm{m}}\right)$ & $69.31 \mathrm{mH}$ \\
\hline Number of pole $(\mathrm{p})$ & 4 \\
\hline Rated speed $(\mathrm{N})$ & $1500 \mathrm{rpm}$ \\
\hline Inertia $(\mathrm{J})$ & $0.089 \mathrm{Kg}$-square meter \\
\hline
\end{tabular}
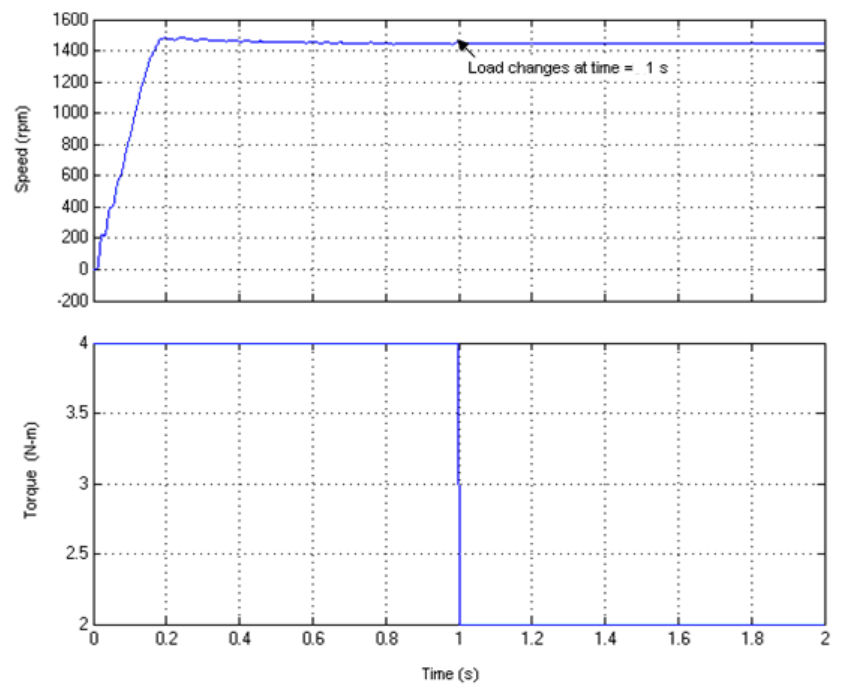

Figure 5 (a). Fuzzy controller response with triangular membership function at load step change from $4 \mathrm{~N}-\mathrm{m}$ to $2 \mathrm{~N}-\mathrm{m}$ at $\mathrm{t}=1 \mathrm{~s}$. 
The membership functions used for error and change in error are changed and simulated. The simulated response of the fuzzy controller for set reference speed with a triangular membership function is given in Fig. 5(a). The results of using seven linguistic variables and 49 rules are given. The transient response is satisfactory without any oscillations and minimum settling time. The steady state error is also at its minimum in using the triangular membership functions. It can be found that the error is minimum for set point reference speed and negligible speed overshoot at sudden load change.
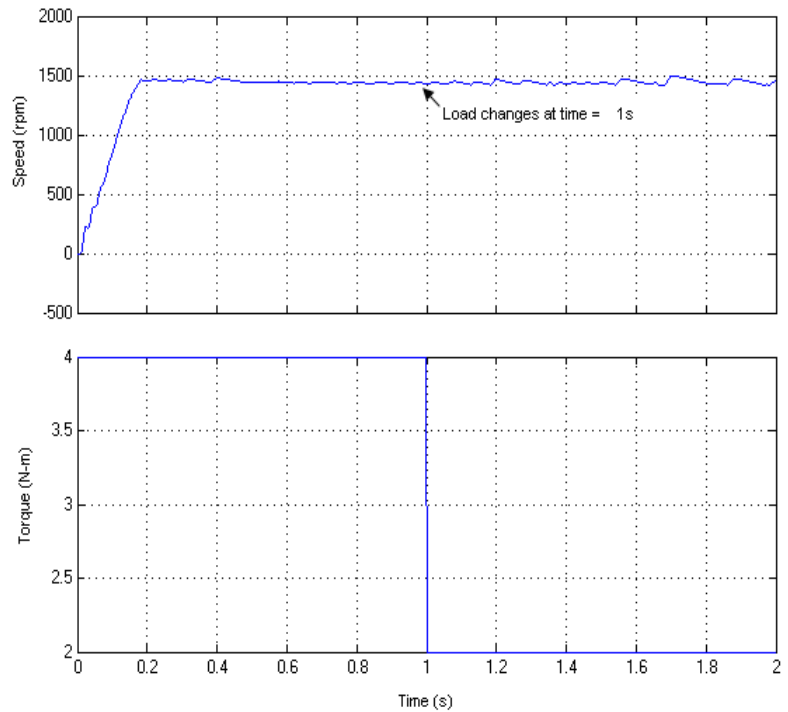

Figure 5 (b). Fuzzy controller response with trapezoidal membership function at load step change from $4 \mathrm{~N}-\mathrm{m}$ at $\mathrm{t}=1 \mathrm{~s}$.
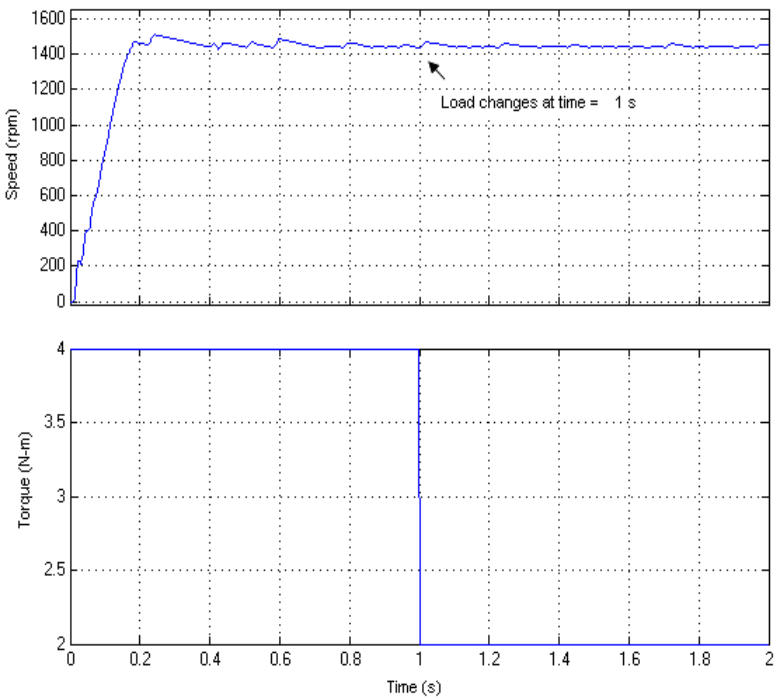

Figure 5 (c). Fuzzy controller response with Gaussian membership function at load step change from $4 \mathrm{~N}-\mathrm{m}$ to $2 \mathrm{~N}-\mathrm{m}$ at $\mathrm{t}=1 \mathrm{~s}$.

Fig. 5(b) to 5(d) show the results of using trapezoidal, Gaussian and bell shaped membership functions, respectively. The transient response is slightly affected for the given set of rules irrespective of the membership functions used. But the error (set point reference speed is not follow measured speed) is increased for other membership functions compared to the triangular membership function. It can be seen from the response curves that the steady state error is reduced for membership functions with the reduced value of the nucleus. For triangular membership function, the nucleus is a single point and is the height of the function. In Fig. 5(b) to 5(d) show the results of using trapezoidal, Gaussian and bell shaped membership functions, respectively. It could be seen that a small overshoot at load torque disturbance and small oscillation in speed response but in Fig. 5(a) shows that negligible overshoot at load torque disturbance and no oscillation in speed response.
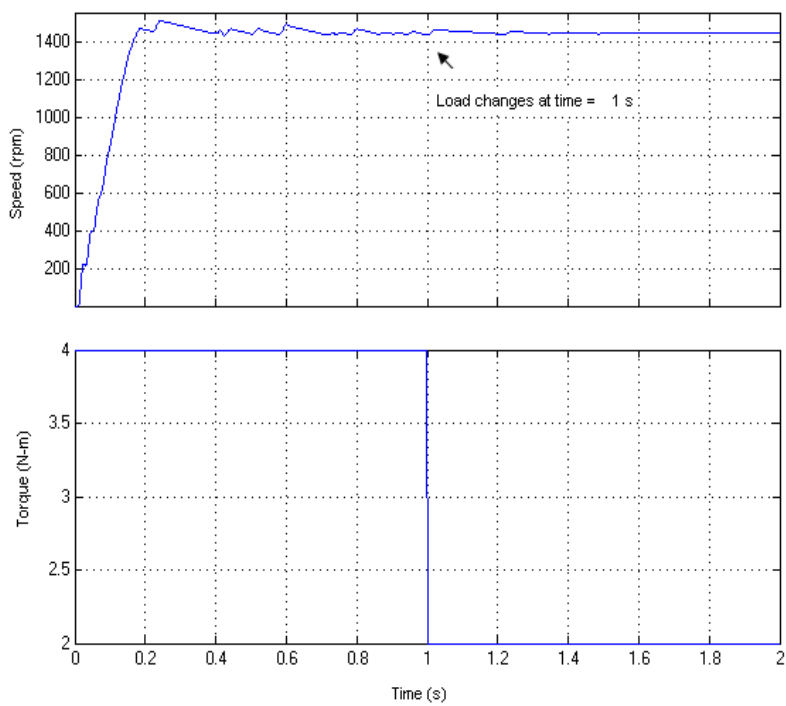

Figure 5 (d). Fuzzy controller response with bell shaped membership function at load step change from $4 \mathrm{~N}-\mathrm{m}$ to $2 \mathrm{~N}-\mathrm{m}$ at $\mathrm{t}=1 \mathrm{~s}$.

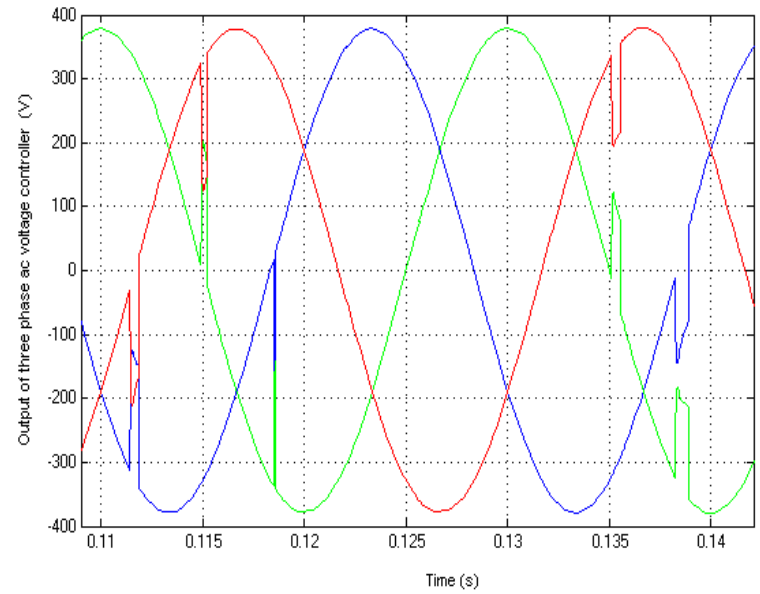

Figure 6. Output voltage of three phase ac voltage controller by Fuzzy controller with triangular membership function.

Fig. 6 shows the three phase output voltage of ac voltage controller by fuzzy controller with triangular membership function. It can be seen that there is no overshoot of three phase output voltage, the controller is used to change the firing angle of the ac voltage controller and thereby, the controlled voltage fed to stator of induction motor to regulate the speed.

\section{CONCLUSIONS}

This paper has been successfully demonstrated effect of various membership functions in the fuzzy control of an ac voltage controller for speed control of induction motor drive in Matlab/Simulink simulation. The output voltage of ac voltage controller or stator voltage of induction motor controlled by changing firing angle. The firing angle of ac voltage controller controlled by FC and thereby, the voltage fed to stator of induction motor to regulate its speed. The effect of various 
membership functions in the fuzzy control of an ac voltage controller for speed control of induction motor drive scheme has proved to be robust and its triumph has been validated with set point reference speed and load torque change load, while the motor is running at rated speed but the simulation results showed that the triangular membership functions for fuzzifying error and change in error reduces steady state error in speed response compared to trapezoidal, Gaussian and bell shaped membership functions. Use of seven linguistic variables has given a better response for fuzzifying error and change in error.

\section{REFERENCES}

[1] Lipo, T.A., "The analysis of induction motors with voltage controlled by symmetrically triggered thyristors, "IEEE Trans. Power Apparatus and Systems, vol. PAS-90, pp. 515-525.

[2] Hamed .S and Chalmers. B, "Analysis of variable-voltage thyristor controlled induction motors," IEE Proc. vol. 137(3), PT.B, PP. 184-193, May 1990.

[3] Kamaike, H. "Elevator speed control system," U.S. Patent 4052651 , Oct. 1977.

[4] Morters et. al, "Control system for regulating the speed of an electric motors," U..S. Patent 4093898, June 1978.

[5] A.I Alolah, Ali M. Eltamaly, and R. M. Hamouda, "Control limits of three - phase ac voltage controller under induction motor load," Conf.Proc. Of IEEE, International conference on electrical machines, ICEM06, Chania, Crete island, Greece, Sept. 2006.

[6] Li, W. X., Lui, J.G., LIU, M.S., and ZHAO, J. "Design of intellegient soft-start controller for induction motor," Proc. of the third international conference on machine learning and cyberbetics, Shanghai, August 2004, pp. 908-912.

[7] H.A. Ashou, R.A. Ibrahim, 'Comparison analysis of ac voltage controller based on experimental and simulated application studies," Computer engineering and systems, The 2006 international conference 0n 2006 P, pp. 79-84.
[8] V S C Raviraj and P C Sen. "Comparative Study of Proportional-Integral, Sliding Mode and Fuzzy Logic Controllers for Power Converters,". IEEE Transactions on Industry Applications, vol 33, no 2, March/April 1997, pp 518-524.

[9] B K Bose. "Power Electronics and Motor Drives - Recent Technology Advances," Proceedings of the IEEE International Symposium on Industrial Electronics, 2002. ISIE 2002, pp 22- 25.

[10] Rajaji, L, Kumar. C,"Adptive neuron fuzzy based soft starting of voltage controlled induction motor dive," Southeastcon, 2008, IEEE, April 2008, pp. 448-453.

[11] P Mattavelli, L Rossetto and G. Spiazzi. "General Purpose Fuzzy Controller for dc-dc Converters," IEEE Transactions on Power Electronics, vol 12, no 1, January, 1997, pp 7986.

[12] M K Habib. "Designing Fuzzy Logic Controllers for dc Servomotors Supported by Fuzzy Logic Control Development Environment," The Twenty-seventh Annual Conference of the IEEE Industrial Electronics Society, IECON '01, vol 3, 2001, pp 2093-2098.

[13] Rashidi, M Rashidi and A Hashemi-hossieini. "Speed Regulation of dc Motors using Intelligent Controllers," Proceedings of IEEE Conference on Control Applications, 2003, pp 925-930.

[14] M.G. Solveson, B. Mirafzal, "Soft- started induction motor modeling and heating issues for different starting profiles using flus linkages $\mathrm{ABC}$ frame of refernce, IEEETrans. Industry Application, vol. 42, no. 4, pp. 973982, JUNE/August 2006.

[15] Zhao and B K Bose. "Membership Function Distribution Effect on Fuzzy Logic Controlled Induction Motor Drive," 0-7803-7906-3/ 03, pp 214-219.

[16] F Cupertino, M Dotoli, V Giordano, B Maione and L Salvatore. "Fuzzy Control Experiments on dc Drives using Various Inference Connectives," Proceedings of the IEEE International Conference on Fuzzy Systems, FUZZIEEE'02, 2002, pp 52-57. 